GEFAD / GUJGEF41(2): 765-795(2021)

\title{
İyi Öğretmen Ölçeğinin Türk Kültürüne Uyarlanması Çalışması*
}

\section{A Study of Adaptation of the Good Teacher Scale into Turkish Culture}

\author{
İlhan ILLTER ${ }^{1}$ \\ ${ }^{1}$ Kahramanmaraş Sütçü İmam Üniversitesi, Türkçe ve Sosyal Bilimler Eğitimi Bölümü. \\ iilter@ksu.edu.tr
}

Makalenin Geliş Tarihi: 02.10.2020

Yayına Kabul Tarihi: 14.04.2021

\section{$\ddot{O} Z$}

Bu araştırmada Devine, Fahie ve McGillicuddy (2013) tarafindan geliştirilen "Iyi Öğretmen Ölçeği”nin Türk kültürüne uyarlanması amaçlamıştır. Bu amaçla çalışmanın verileri bir yüksekögretim kurumunun ĕgitim fakültesinin farklı bölümlerinde öğrenim gören 350 ögrenciden elde edilmiştir. Araştırmada ilk olarak orijinal ölçek uzman görüşleri doğrultusunda dil ve kültürel açıdan Türkçeye uyarlanmış ve ölçeğin dilsel eşdeğerliği sağlanmıştır. Daha sonra ölçeğin yapı geçerliği çalışmaları için birinci ve ikinci düzey doğrulayıcı faktör analizleri yapılmıştır. Ölçeğin güvenirlik çalışmaları için ise Cronbach Alfa iç tutarlık katsayısı hesaplanmıştır. Birinci ve ikinci düzey DFA sonuçları birlikte değerlendirildiğinde ölçeğin orijinal formunda yer alan beş faktörlü yapının araştırmanın örneklem grubu üzerinde doğrulandiğl görülmüştür. Ölçeğin faktörleri "Öğretme ve öğrenme tutkusu”, "Sosyal ve ahlaki boyut", "Yansitıcı uygulayıcı", "Öğrenmeyi etkili planlama ve yönetme” ve "Çocuklara/gençlere sevgi” şeklindedir. Ölçeğin bütünü için hesaplanan Cronbach Alfa iç tutarlık katsayısının .86 olduğu; ölçekteki faktörler için hesaplanan iç tutarlık katsayılarının ise .77 ile .82 arasında değiştiği bulunmuştur. Araştırmanın bulgularl, Türk kültürüne uyarlanan İyi Öğretmen Ölçeği'nin öğretmen adaylarının iyi öğretmen özellikleri hakkındaki farkındalık düzeylerini ölçmede geçerli ve güvenilir bir ölçme aracı olduğunu göstermektedir.

Anahtar S̈̈zcükler: Ĕ̆itim, Öğretmen, İyi öğretmen.

\footnotetext{
* Alıntılama: İlter, İ. (2021). İyi öğretmen ölçeğinin Türk kültürüne uyarlanması çalışması. Gazi Üniversitesi Gazi Ĕ̈itim Fakültesi Dergisi, 41(2), 765-795.
} 


\section{ABSTRACT}

The aim of the present study is to adapt the "Good Teacher Scale" developed by Devine, Fahie, and McGillicuddy (2013) to Turkish culture. The study data were collected from 350 current undergraduate students who were enrolled in different departments in the education faculty of a higher education institution. In the study, firstly, the original scale was adapted to Turkish in terms of language and culture in line with expert opinions and linguistic equivalence was provided. Next, first and second level confirmatory factor analyses were performed for the construct validity studies of the scale, and the Cronbach Alpha internal consistency coefficient was calculated for reliability studies. First and second level CFA results were evaluated together, the 5-factor structure model in the original form of the scale was confirmed. The sub-factors are as following: "Passion for teaching and learning", "Social and moral dimension", "Reflective practitioner", "Effective planning and management of learning" and "Love for children / young people". The Cronbach Alpha coefficient calculated for the whole scale was .86. The internal consistency coefficients calculated for the factors on the scale ranged from .77 to .82 . Findings of the present study showed that the Good Teacher Scale, which was adapted to Turkish culture, is a valid and reliable measurement instrument for exploring teacher candidates' awareness of the characteristics of good teachers.

Keywords: Education, Teacher, Good teacher. 


\section{GİRIŞ}

Eğitimde nitelikli öğretmenlerin yetiştirilmesi ve öğretmen profesyonelliğinin artırılması konusu en çok üstünde durulan ve tartışılan konuların başında yer almaktadır. Öğretmenlerin eğitim kalitesinin tek ve en önemli belirleyicisi olduğu yaygın olarak kabul edilmektedir. Eğitim sisteminde önemli yerleri olan öğretmenler eğitim sisteminin potansiyel kurtarıcıları olarak görülmektedir. Öğretmenler, eğitimde eşitlik, erişim ve kalite için en etkili ve güçlü güçlerden biri olup sürdürülebilir kalkınmanın ve sürdürülebilir yaşam anahtarıdır. Öğretmen davranıș ve tutumları ile çevresine, kişilik özellikleri ile topluma iyi bir örnek olarak öğrencilerin sezgilerini ve hayal gücü kapasitelerini açığa çıkararak onların yetenekleri, başarısı, benlik algısı, yaşam biçimi ve kişisel ilgi ve değerlerine doğrudan etki edebilmektedir.

Eğitimin kalitesini artırmada önemli bir nokta daha iyi ya da etkili öğretmen anlayışı ve bunun arayışıdır (Biesta, 2015; Markert, 2001; Moore, 2004). Eğitim hizmetine bağlı olan öğretmen, eğitimsel hedeflerin gerçekleştirilmesinde, toplumsal yenileşme, değişism ve dönüşümü sağlamada tanımlanmış önemli rolleri oynamaktadır. Bu anlamda iyi bir eğitim ve o eğitimi sağlayan iyi öğretmenlerin önemi ve eğitimde gerekliliği kuşkusuz açıktır. Toplumsal kalkınma ve gelişmenin temeli eğitimden geçiyorsa kalkınmanın temelini atan öğretmenlerin kaliteli bir eğitimden geçerek iyi öğretmen göstergelerine sahip olmalarının gerekliliği açıktır. Eğitimde ve öğretmen yetiştirme sisteminde iyi öğretmen olgusu bir öğretmenin gerçekten iyi olup olmadığını belirlemek için kritik bir konudur (Jo-Anne, 2011; Millî Eğitim Bakanlığı- MEB, 2006). İyi bir öğretmeni nasıl tanımladığımız ve iyi öğretmen özelliklerini hangi nitelikler kapsamında kabul ettiğimiz önemlidir (Grant, 2015).

İyi öğretmen araştırmaları öğretmenliğin mükemmelliğini tanımlama ve güncel fikirleri ve pedagojik yaklaşımları belirleme çabalarını gütmektedir (Beishuizen, Hof, Van Putten, Bouwmeester ve Asscher, 2001; Benekos, 2016). İyi öğretmen tartışmaları bu konuda iyi öğretmen kavramının net bir tanımını ifade etmenin zor olduğunu (Korthagen, 2004) ancak iyi bir öğretmeni tanımlayan belirli göstergeler olduğunu 
göstermiştir (Kutnick ve Jules, 1993; Porter ve Brobhy, 1987; Sanders, 2002). İyi öğretmen tartışmalarının öğretmenin sahip olması gereken belli yeterlik alanları (ör., öğrenciyi tanıma, öğretme-öğretme süreci, okul-aile-toplum ilişkileri, içerik bilgisi, kapsayıcı pedagoji, müfredat bilgisi, izleme-değerlendirme), olumlu kişisel nitelikler listesiyle ilgili olduğu düşünülmektedir (Barnett, 1994; Becker, Kennedy ve Hundersmarck, 2003; Hyland, 1994; MEB, 2006). Günümüzde iyi bir öğretmen olmak için ise öğretmenin sadece konu bilgisine değil, çeşitli becerilere ve değerlere de sahip olması gerektiği kabul edilmektedir (Noddings, 1992). Araştırmacılar çeşitli bağlamlarda öğrenme kuramları, öğretmen rollerine dair temel düşünce ve uygulamaları göz önünde bulundurarak iyi öğretmenleri çağdaşlarından ayırt eden özellikler tanımlamıştır (Shulman, 2000; Winch, 2017). Bunlar öğretimde yeni durumlar ile karşılaşmaya hazır olan, öğretim sanatının dayandığı disiplinleri anlayan, tutku ve sanatı akademik becerileri ile birleştiren, müfredatın amaç ve kazanımları üzerinde derin düşünen ve yansıtıcı olarak uygulayan şeklinde tanımlanmıştır (Black ve Howard-Jones, 2000; Dewar, 2002; Harden ve Crosby, 2000; Stobaugh, Mittelberg ve Huang, 2020).

\section{İyi Öğretmenin Doğası}

Alan yazında "iyi öğretmen nedir, iyi bir öğretmen nasıl olmalıdır" sorusu üzerine yapılan raştırmalar benzer bulgular göstermiştir. Bu araştırmaların bazılarında çocukları sevme, açıklık ve anlaşılırlık, ilginin uyarılması, öğretme coşkusu, öğrenciler için ilgi ve saygı, alanıyla ilgili yeterli bilgi, çocukların eğitimi konusunda izlenen yöntemlerde deneyimli olma göze çarpmıştır (Arthur ve diğ., 2015; Azer, 2005; Hammer ve diğ., 2010; Howes, Whitebook ve Phillips, 1992; Stronge, Ward ve Grant, 2011). İyi öğretmen doğası üzerine yapılan diğer araştırmalar iyi öğretmenlerin öğrenme faaliyetlerini dikkatli izlediğini, değerlendirdiğini ve açık, kabul edici ve destekleyici, öğrencilere adil ve katılımda ısrarcı olduklarını göstermiş̧ir (Cruickshank ve Haefele, 2001).

İyi bir öğretmen, iyi bir öğrenci yetiştirmede hayati bir role sahiptir. İyi bir öğretmenin öğrenci algısına göre güçlü ve etkili iletişim becerisine sahip olması, öğrencileri motive etme becerisine sahip olması ve konu hakkında sağlam bilgi sahibi olması gerekir 
(Malik ve Bashir, 2015). İyi bir öğretmen, birey olarak öğrenciye odaklanan, eğitici, güvenilir, beklenmeyen sorunları çözebilen ve rehberlik sağlayan öğretimde eşsiz firsatlar sunan, her öğrenci ile seviyesinde bağlantı kuran ideal bir eğitimcidir (Arnon ve Reichel, 2007). Winch (2017) iyi öğretmeni ne yaptığ konusunda yeterince ciddi olmakla kalmayıp aynı zamanda hedeflerini önemli ölçüde, belki de çağdaşlarının çoğundan daha fazla gerçekleştiren kişi olarak tanımlamıştır (s.188). Araştırmacılara göre iyi öğretmeni her şeyden önce iyi bir insan, toplumun gereksinimlerine göre ideal anne-babayı, ideal çalışanı, ideal vatandaşı yetiştiren iyi bir rol modeli olarak tanımlamıştır (Borich, 2014). Bu anlayışa göre iyi öğretmen öğrencilerin öğrenme sürecini düzenleyen ve öğrenme yolculuğunda onlara bu hususlarda rehberlik eden kişidir. Walker (2008) bir öğretmeni iyi kılan unsurların on iki kategoriye ayrıldığını tespit etmiştir: hazırlık, pozitiflik, yüksek beklentiler, yaratıcılık, adil, öğrencilere kişisel bir dokunuş sergilemek, aidiyet duygusu geliştirmek, merhametli olmak, mizah anlayışına sahip olmak, öğrencilere şefkat göstermek, affetmek ve hataları kabul etmek. Cruickshank ve Haefele (2001) ise iyi öğretmenin farklı yönlerini temsil eden on öğretmen vizyonunu tarif etmiştir. Bunlar ideal öğretmen, analitik öğretmen, etkili öğretmen, uzman öğretmen, yansitıc1 öğretmen, memnun edici öğretmen, saygilı öğretmen, yetkin öğretmen ve kapsayıcı öğretmendir. Bu araştırmacılara göre tüm bu kategorilerin hiçbiri birbirini dışlamaz ve iyi öğretmenin olası örneklerini yansıtacak niteliktedir. Azer (2005) ise iyi bir öğretmeni şu özellikler tanımlamıştır: 1) öğretimde liderlik gösterir, 2) öğretime çok çeşitli beceri ve yetenekler getirir, 3) öğrencileri ve iş arkadaşlarını motive eder, 4) etkileşim kurar ve saygı ile iletişim kurar, 5) çeşitliliği teşvik eder ve takdir eder, 6) işe kendini adamış, 7) açık ve güvenilir bir öğrenme ortamını teşvik eder, 8) eleştirel düşünmeyi teşvik eder, 9) yaratıcı çalışmayı teşvik eder, 10) öğretim becerilerini sürekli olarak geliştirmeye çalışır, 11) takım çalışmasını vurgular ve 12) olumlu geribildirim sağlar. 


\section{Araştırmanın Amacı}

Uluslararası alan yazında iyi öğretmen olgusu üzerinde araştırmaların uzun bir geleneği olmasına rağmen (ör., Arnon ve Reichel, 2007; Benekos, 2016; Connell, 2009; Devar, 2002; Grant, 2015; Hummerstone ve Parsons, 2020; McIntyre ve Battle, 1998; Kember, Jenkins ve Chi-Ng, 2004; Morrison ve Evans, 2018; Mullock, 2003; Murphy, Delli ve Edwards, 2004; Kutnick ve Jules, 1993; Peterson ve Arthur, 2020; Reid, Singh, Santoro ve Mayer, 2011; Thomas, 1998), Türkiye'de iyi öğretmen profiline ve doğasına odaklanan çalışmalar henüz yeterli düzeyde değildir (Aypay, 2011; Deniz, 1998; Hoşgörür, 2012; Inan, 2014; Işıłktaş, 2015; Kızıltepe, 2002; Oruç, 2008; Ubuz ve Sarı, 2009). Ayrıca Türkiye'de öğretmen adaylarının ya da öğretmenlerin iyi öğretmen özellikleri hakkındaki farkındalık düzeylerini değerlendiren bir ölçme aracına henüz rastlanmamıştır. İyi öğretmenle ilgili çalışmaların çoğunlukla nitel ağılıklı olduğu görülmüştür. Bu gerekçeler doğrultusunda yapılan bu araştırmada Devine, Fahie ve McGillicuddy (2013) tarafından geliştirilen İyi Öğretmen Ölçeği’nin Türk kültürüne uyarlama çalışması yapılmıştır. İyi Öğretmen Ölçeği'nin Türk kültürüne uyarlanmasının nedeni ölçeğin öğretmenlik mesleğinde nitelikli bir öğretmen olmanın çeşitli yönlerini temsil etmesi bakımından aday öğretmenlerin ya da şu anda öğretmenlik mesleğini yürüten öğretmenlerin iyi öğretmen hakkındaki farkındalık düzeylerini belirlemek adına yararlı bir çerçeve sunacağı beklentisidir. Ölçek, iyi bir öğretmenin özünü neyin oluşturduğuna dair bir çerçeve sağlayacak bir bakış açısı ve iyi bir öğretmenin ne olduğu üzerine temel göstergeler sunabilmektedir (Devine ve diğ., 2013). Bu göstergeler, öğrenmeyi etkili planlama ve yönetme, çocuk sevgisi, sosyal ve ahlaki farkındalık, yansıtıcı uygulama davranışları, profesyonel büyüme, öz-eleştirel uygulamalar ve öğrenci ilişkileri gibi bir dizi farklı sınıflandırmaları içermektedir. 
Öğretmenler genel olarak 'iyi ya da etkili öğretmen' imajını algılama biçimlerine göre profesyonel olarak hareket eder ve gelişirler (Wilson, Cooney ve Stinson, 2005). Öğretmen eğitimcilerinin sorumluluklarından biri de, iyi bir öğretmenin özünü oluşturan fikirlerin belirlenmesini kolaylaştırmaktır (Lavy ve Shriki, 2008). Eğitim sisteminde istenilen niteliğin sağlanması için iyi bir öğretmenin özünü neyin oluşturduğuna dair temel ölçütleri belirlemeye dayalı araştırmalara önemle ihtiyaç vardır. Öğretmenlik mesleğini yürüten veya yarının öğretmenlerinin iyi öğretmen olgusu üzerine farkındalıklarının belirlenmesi ve iyi öğretmen göstergelerine sahip olup olmadıklarının incelenmesi önemlidir. Çünkü iyi öğretmen araştırmaları öğretmen eğitim programlarının tasarımı ve öğretmen eğitimcilerinin çalışmalarını belirleyen temel bilgilere katkı sağlayabilmektedir. Ayrıca iyi öğretmeni neyin oluşturduğuna dair fikir ve düşüncelerin daha iyi anlaşılması iyi bir öğretmen olmak için öğretmenlik mesleğinin gerektirdiği niteliklerinin tartışılmasını ve ölçülmesine yönelik mekanizmalar oluşturulmasını yardımcı olabilir. Öte yandan iyi öğretmeni neyin oluştuğuna dair güncel fikirler eğitim kurumlarının tasarımına yerleştirilmiştir ve iyi öğretmen etkili öğretmen eğitimi mekanizması ile ilgili yeni anlayışlara ve güncel uygulamalarda önemli bir yer edinmektedir (Connell, 2009). Bu bağlamda, Devine ve diğerleri (2013) tarafından geliştirilen İyi Öğretmen Ölçeği’nin Türk kültürüne uyarlama çalışması hem Türk Eğitim Sisteminde iyi öğretmen olgusunun ölçülmesine kaynaklık etmesi hem de öğretmen profesyonelliğini geliştirme üzerine yeni fikir, yaklaşım, bilgilerin tartışılması açısından yararlı görülmekte olup; yapılan bu araştırmanın temel amacını oluşturmaktadır. 


\section{YÖNTEM}

\section{Araştırma Modeli}

$\mathrm{Bu}$ araştırma, İyi Öğretmen Ölçeği'nin (IÖÖ) Türk kültürüne uyarlandığı bir ölçek uyarlama çalışmasıdır. Araştırmada betimsel araştırma desenlerinden tarama modeli kullanılmıştır. Araştırma kapsamında, ölçeğin dil eşdeğerliğinin sağlanması, yapı geçerliğinin incelenmesi ve güvenirlik çalışmalarının yürütülmesi hedeflenmiştir.

\section{Katılımcılar}

Araştırmaya ilk olarak İyi Öğretmen Ölçeği'nin (IÖÖ) dil geçerliği çalışması için bir yükseköğretim kurumunun eğitim fakültesinde İngilizce Öğretmenliği Bölümünde öğrenim gören otuz öğrenci katılmıştır. Araştırmanın ikinci çalışma grubu ile İÖÖ'nün yapı geçerliği için doğrulayıcı faktör analizi (DFA) ve güvenirlik çalışmaları yapılmıştır. İkinci çalışma grubu bir yükseköğretim kurumunda eğitim fakültesinde 2020-2021 öğretim yılında güz yarıyılında farklı programlarda ve dördüncü sınıfta öğrenim gören 350 öğrenciden oluşmaktadır. Araştırmanın verileri kolay ulaşılabilir örnekleme yöntemi ile seçilen iki farklı çalışma grubundan elde edilmiştir. Kolay ulaşılabilir örnekleme yöntemi araştırmacının hedefi olan evrenden örneklemini oluştururken ulaşabileceği en kolay unsurlara yönelmesi olarak ifade edilebilir (Patton, 2014). DFA ve güvenirlik analizlerin yapıldığı çalışma grubunu 182 erkek ve 168 de kadın öğrenci oluşturmaktadır.

\section{Veri Toplama Araçları}

\section{Orijinal İyi Öğretmen Ölçeği (İÖÖ)}

$\mathrm{Bu}$ araştırmada veri elde etmek için Devine ve diğerleri (2013) tarafından geliştirilen İyi Öğretmen Ölçeği (Good Teacher Questionnaire) kullanılmıştır. Ölçek, öğretmenlerin iyi öğretmen özellikleri ile ilgili farkındalık düzeylerini ölçmek amacıyla tasarlanmıştır. İyi Öğretmen Ölçeği toplam 26 maddeden oluşmaktadır. Ölçeğin beş faktörlü bir yapısı bulunmaktadır. Faktör 1, "öğretme ve öğrenme tutkusu”, Faktör 2, "sosyal ve ahlaki 
boyut” ve Faktör 3 "yansıtıcı uygulayıcı”, Faktör 4 “öğrenmeyi etkili planlanma ve yönetme” ve Faktör 5 ise “çocuklara/gençlere sevgi’ dir. Bu faktörler iyi öğretmenin özelliklerini temsil eden ana göstergeler olup iyi öğretmen olgusuna dayalı bütünleşik yapıyı ölçmektedir (Devine ve diğ., 2013). Ölçeğin tamamı olumlu ifadelerden oluşmaktadır ve her bir maddeye göreli önem atfedilmektedir. Her bir madde (1) "Daha az önemli” 'den (7) “Son derece önemli” 'ye uzanan 7'li Likert tipi bir ölçek olarak yapılandırılmıştır. Ölçeğin alt boyutlarına ilişkin puan hesaplanmasına ek olarak ölçeğin bütününe ilişkin olarak toplam puan hesaplanabilmektedir. Ölçekten alınan puanların yükselmesi, öğretmenlerin iyi öğretmenlerin özellikleri hakkındaki farkındalık düzeylerinin yüksek olduğunu göstermektedir. Ölçeğin alt boyutlarından alınan puanların yükselmesi ise ilgili faktöre ilişkin farkındalığın yüksek düzeyde olması anlamına gelmektedir. Orijinal ölçeğin geliştirilmesi aşamasında ölçeği geliştiren araştırmacılar ilgili alan yazını incelemiş ve ölçekte yazılacak maddelere ölçüt olarak kullanılacak iyi bir öğretmenin sahip olduğu nitelikler ve becerileri hakkında belirli göstergeler tanımlamıştır. Ölçeği geliştiren araştırmacılar tarafından ölçeğin yapı geçerliği için açımlayıcı faktör analizi yapılmış. AFA sonuçları, ölçeğin toplam varyansının \%71.79'unu açıklayan beş faktörlü bir yapıya sahip olduğunu göstermiştir. Ancak AFA sonucu ortaya konulan beş faktörlü modeli doğrulamak için söz konusu araştırmacılar tarafından doğrulayıcı faktör analizi yapılmamıştır. Orijinal ölçeğin bütünü için Cronbach Alfa iç tutarlık katsayısı .70’in üzerinde bulunmuştur. Ölçeğin alt boyutlarının Cronbach Alfa iç tutarlık katsayısı "öğretme ve öğrenme tutkusu” için .78, “sosyal ve ahlaki boyut” için .84, "yansıtıcı uygulayıcı” için .89, "öğrenmeyi etkili planlanma ve yönetme" için .82 ve "çocuklara/gençlere sevgi" için .78 olarak hesaplanmıştır.

\section{İșlemler}

İyi Öğretmen Ölçeği'nin yapı geçerliği çalışmaları kapsamında araştırmanın verileri çevrimiçi formlar (online ölçek) ile araştırmanın ikinci çalışma grubundan elde edilmiştir. Verileri elde etmek için öncelikle araştırmaya dahil olan öğrencilerin kişisel e-posta bilgilerine ulaşmak amacıyla ilgili kurumdan gerekli izinler alınmıştır. İzin 
işlemlerinin ardından araştırmacı (yazar) uyarlayarak son hali verdiği ölçeğin Türkçe formunu Google docs sistemini kullanarak online ölçek formatına dönüştürmüştür. Google formlara İyi Öğretmen Ölçeği'ndeki 26 madde girilmiş ve katılımcılardan seçeneklerinden birini tercih etmeleri istenmiştir. Bununla birlikte toplanan verilerin sadece bilimsel amaçlı kullanılacağı ve üçüncü kişilerle paylaşılmayacağı belirtilmiştir. $\mathrm{Bu}$ adımdan sonra toplam 420 öğrencinin kişisel e-postasına online olarak düzenlenen ölçek formu internet ortamından gönderilmiştir. Çalışmaya katılımda gönüllülük temel alınmış ve öğrencilerin ölçeğe erişimi sağlanmıştır. Bu yolla toplam 385 katılımcıdan dönüş sağlanabilmiştir.

\section{Verilerin Analizi}

İyi Öğretmen Ölçeği'nin faktör yapısının Türkiye örnekleminde geçerli olup olmadığını tespit etmek için SPSS AMOS 23.0 veri analizi programı kullanılarak iki farklı düzeyde DFA gerçekleştirilmiştir. Araştırmada model uyum indeksleri olarak Ki-kare/ serbestlik derecesi, $\chi^{2} /$ sd, Yaklaşık Hataların Ortalama Karekökü (RMSEA), İyilik Uyum İndeksi (GFI), Tucker-Lewis İndeksi (TLI), Karşılaştırmalı Uyum İndeksi (CFI) kullanılmıştır. Ki-kare/ $\left(\chi^{2}\right)$ serbestlik derecesi (sd) oranının 2'den küçük olması iyi uyumu göstermektedir. RMSEA değerinin .05 ve altında olması ölçeğin iyi bir uyuma sahip olduğunu göstermektedir (Brown, 2006; Jöreskog ve Sorbom, 1996). TLI, CFI ve GFI değerlerinin .90 ve üzeri olması ölçme aracının kabul edilebilir bir uyum iyiliği değerine sahip olduğuna işaret etmektedir (Byrne, 1998; Hu ve Bentler, 1999; Kline, 2005; Schermelleh-Engel, Moosbrugger ve Müler, 2003). Faktör yapısı belirlenen alt boyutlar için Cronbach Alfa iç tutarlık güvenirlik katsayıları ve madde-toplam korelasyonları hesaplanmıştır. Cronbach Alfa iç tutarlılık güvenirlik, korelasyon katsayıları için ise SPSS 21.0 veri analizi programı kullanılmıştır.

Ölçeğin geçerlik ve güvenirlik analizleri öncesinde tek değişkenli uç değerler, çok değişkenli uç değerler, tek değişkenli normal dağılım, çok değişkenli normal dağı̆lım, doğrusallık ve çoklu bağlantı gibi gerekli varsayım testleri incelenmiştir (Tabachnick ve Fidell, 2013). Online ölçek yoluyla 385 katılımcıdan toplanan veriler arasında kayıp 
veri olmadığından tüm veriler işleme alınmıştır. Veri setinde olası tek değişkenli uç değerler için standartlaştırılmış $\mathrm{z}$-değerleri incelenmiş ve yirmi kişiye ait $\mathrm{z}$ değeri -3 ile + 3 sınırları dışında olduğu için veri analizine dahil edilmemiştir (Tabachnick ve Fidell, 2013). Çok değişkenli aykırılık için de Mahalanobis uzaklığı incelenmiştir (Alpar, 2013). Her bir katılımcı için Mahalanobis uzaklık değeri $\mathrm{p}<.001$ anlamlılık düzeyinde Ki-kare değeri ile karşılaştırılmış ve çok değişkenli uç değer olduğu belirlenen 15 kişi daha veri analizinden çıkarılmıştır. Sonuç olarak toplam 35 kişinin analiz dışında bırakılması ile birlikte nihai olarak 350 katılımcıya ait veriler üzerinden istatistiksel analizler yapılmıştır. Normallik varsayımları için tüm değişkenlerin çarpıklık (skewness) ve basıklık (kurtosis) değerlerine bakılmıştır. 26 maddeden 5'inin çarpıklık ve basıklık değerlerinin $-1,+1$ ranjının dışında olduğu görülmüştür (Finney ve DiStefano, 2006). Tabachnick ve Fidell'e (2013) göre normallik varsayımının sağlanması için basıklık ve çarpıklık değerlerinin +1.5 ile -1.5 arasında olması yeterlidir. Değiş̧kenlerin büyük çoğunluğunun bu koşulu sağlaması, örneklem sayısının yeterli olması ve verinin diğer sayıltıları sağlaması sebebiyle bu sayıltının kısmen sağlandığı dikkate alınarak analiz sürecine devam edilmiştir. Son olarak DFA'nın sayıltılarından biri olan değişkenler arasında çoklu bağlantının olmaması durumudur. Çoklu bağlantı varsayımına ilişkin olarak İÖÖ ile ölçeği oluşturan faktörleri arasındaki ilişkinin belirlenmesi için Pearson korelasyon testi yapılmış ve korelasyon katsayıları incelenmiştir. Ölçeğin alt boyutları arasında orta ve yüksek düzeyde ve anlamlı düzeyde ilişkiler bulunduğu görülmüştür. Korelasyon değerlerinin .90 'ın altında olması nedeniyle, çoklu bağlantı varsayımının karşılandığı ifade edilebilir (Çokluk, Şekercioğlu ve Büyüköztürk, 2016).

\section{Etik Kurallara Uygunluk}

$\mathrm{Bu}$ çalışmanın her aşamasında etik ilke ve kurallara uyulmuştur. Araştırma verilerinin elde edilme aşamasında katılımcılara gerekli bilgilendirmeler yapılmış ve tamamen gönüllülük esası kapsamında çalışma yürütülmüş̧ür. Araştırmada yararlanılan kaynaklara bilimsel kurallara uygun bir şekilde atıf yapılmıştır. Araştırma 
Kahramanmaraş Sütçü İmam Üniversitesi Sosyal ve Beşerî Bilimler Etik Kurulunun 24.08.2020 tarih ve E. 31621 sayılı kararı ile yürütülmüştür.

\section{BULGULAR}

\section{İyi Öğretmen Ölçeğinin Türkçeye Uyarlaması}

\section{Dil Geçerliğinin İncelenmesi}

Orijinal İyi Öğretmen Ölçeği’nin dili İngilizcedir. Ölçeğin Türkçeye uyarlama sürecinde birtakım adımlar izlenmiştir. Uyarlama sürecinde ilk olarak, söz konusu ölçeği geliştiren sorumlu yazar Dr. Dympna Devine ile e-mail yoluyla iletişime geçirilerek ölçek uyarlama için gerekli izin alınmıştır. Bu adımdan sonra ölçeğin İngilizce' den Türkçeye çevirisi yapılmıştır. Ölçeğin uyarlama çalışması Ægisdóttir, Gerstein ve Çınarbaş (2008) tarafindan önerilen ölçek uyarlama adımları izlenerek yürütülmüştür. Öncelikle İÖÖ ile ölçülmek istenen iyi öğretmenlerin özellikleri ve bu özellikleri tanımlayan faktörlerin yapısının Türk Eğitim Sisteminde mevcut olduğuna, başka bir kültür için hazırlanmış olan bir ölçme aracının uyarlanmasının Türk Eğitim Sisteminde karşılık bulacağına, anlamlı olacağına alanında uzmanların görüşlerine başvurularak karar verilmiştir. Yabancı dilden yapılan ölçek uyarlaması çalışmalarında ölçek maddelerinin uyarlama yapılacak dil ve kültüre uyumlu olması büyük önem taşımaktadır. Bu amaçla İÖÖ’nün Türkçeye uyarlanma sürecinde öncelikle orijinal ölçeğin maddeleri ve cevaplama seçeneklerinin her iki dile hakim olan ve öğretmen eğitimi ve niteliği alanında çalışmaları bulunan iki uzman öğretim üyesi tarafından Türkçeye çevrisi yapılmıştır. Ölçeğin maddelerinde yer alan kavramların her iki dilde de benzer anlamlara sahip olup olmadığı veya aynı yapıları ölçüp ölçmediği Sireci, Patsula ve Hambleton (2005) tarafından önerildiği şekilde her iki dili iyi düzeyde bilen iki konu alanı uzmanı tarafından incelenmiştir.

Uzman görüşleri doğrultusunda, İÖÖ’nün Türkçe formunun içerik geçerliği açısından ölçülmek istenen özelliği temsil etme gücünün yeterli olması için ölçek maddelerinde birtakım düzenlemelere gidilmiştir. Çalışmada orijinal ölçeğe bağlı kalmak ile beraber 
iyi öğretmenin özelliklerini yansıtmak amacıyla ölçmek maddeleri çevrilirken Türk kültürüne uygun ifadeleri barındıracak şekilde düzenlenmeler yapılmıştır. Bu adımdan sonra söz konusu ölçeğin maddelerinin anlaşllabilirliği ve dilbilgisi açısından incelenmesi için Türkçe eğitimi alanında iki öğretim üyesinden görüş alınmıştır. Gelen görüş ve öneriler doğrultusunda ölçek maddelerinin açık ve anlaşılır olduğu iyi veya etkili bir öğretmenin özünü oluşturan belirli ifadeleri yansıtabildiği sonucuna varılmış ve ölçek geçerlik ve güvenirlik çalışmalarının yapılması için hazır hale gelmiştir. Ölçeğin dil eş değerliğini incelemek için birinci çalışma grubunu oluşturan öğrencilere yaklaşık iki hafta arayla ölçeğin İngilizce ve Türkçe formları uygulanmıştır. Uygulama ile öğrencilerden alınan aynı numaralı iki form arasındaki ilişki Pearson korelasyon katsayısı ile hesaplanmıştır. İngilizce ve Türkçe formlardaki maddeler arasındaki korelasyon katsayıları .715 ile .852 arasında değişmektedir $(\mathrm{p}<.001)$. Bu sonuç iki ölçek formu arasında anlamlı düzeyde yüksek bir ilişki bulunduğunu göstermektedir. İngilizce ve Türkçe formlardan elde edilen puanların ortalamaları arasında anlamlı bir farklılık olup olmadığını incelemek için bağımlı gruplar t-testi analizi yapılmıştır. Elde edilen sonuçlar ölçeğin her iki formunun puanlarının ortalamaları arasında anlamlı bir farklılığın bulunmadığını göstermiştir ( $>$ > .05). Bu sonuçlar 1şı̆̆ında İyi Öğretmen Ölçeği’nin Türkçe forumunun dilsel eşdeğerliğinin sağlandığı ifade edilebilir.

\section{İyi Öğretmen Ölçeği’nin Geçerliğine İlişkin Bulgular}

\section{Yapı Geçerliği: Doğrulayıcı Faktör Analizi}

Orijinal ölçeği geliştiren yazarlar tarafından İÖÖ’nün faktör Türkiye'de öğrenim gören öğretmen adayları örneklemi üzerinde doğrulanıp doğrulanmadığını belirlemek için birinci düzey ve ikinci düzey DFA gerçekleştirilmiştir. Birinci düzey doğrulayıcı faktör analizi İÖÖ’nün orijinal ölçekte yer alan birbirinden bağımsız beş faktör ve 26 maddeli yapı temel alınarak yapılmıştır. Birinci düzey DFA sonucu ile elde edilen veriler Şekil 1 'de gösterilmişsir.

Şekil 1 incelendiğinde, İÖÖ'nün Türkçe formunun beş faktör ve 26 maddeli yapısı üzerinde hiçbir modifikasyon yapılmadan uyum indekslerinin $\left(\chi^{2} / \mathrm{sd}\right)=3.69$, 
RMSEA $=.079, \mathrm{CFI}=.87, \mathrm{GFI}=.86, \mathrm{TLI}=.85)$ yeterli olmadığı ve iyileştirilmesi gerektiğine karar verilmiştir. Uyumsuzluk yaratan durum ve maddelerin kontrolü için faktör yükleri, modifikasyon indeksleri ve standardize edilmiş regresyon yük değerleri incelenmiştir (Harrington, 2009). Orijinal ölçeğin yapı geçerliğine yönelik yapılan birinci düzey DFA modelinde "çocuklara/gençlere sevgi" alt boyutunda yer alan bir maddenin regresyon yük değerinin .30 'dan düşük olması nedeniyle ölçekten çıkarılması gerekli görülmüştür (Büyüköztürk, 2017). Ayrıca kurgulanan modelde daha iyi uyum indeksleri elde etmek için modifikasyon önerileri incelenmiştir. 


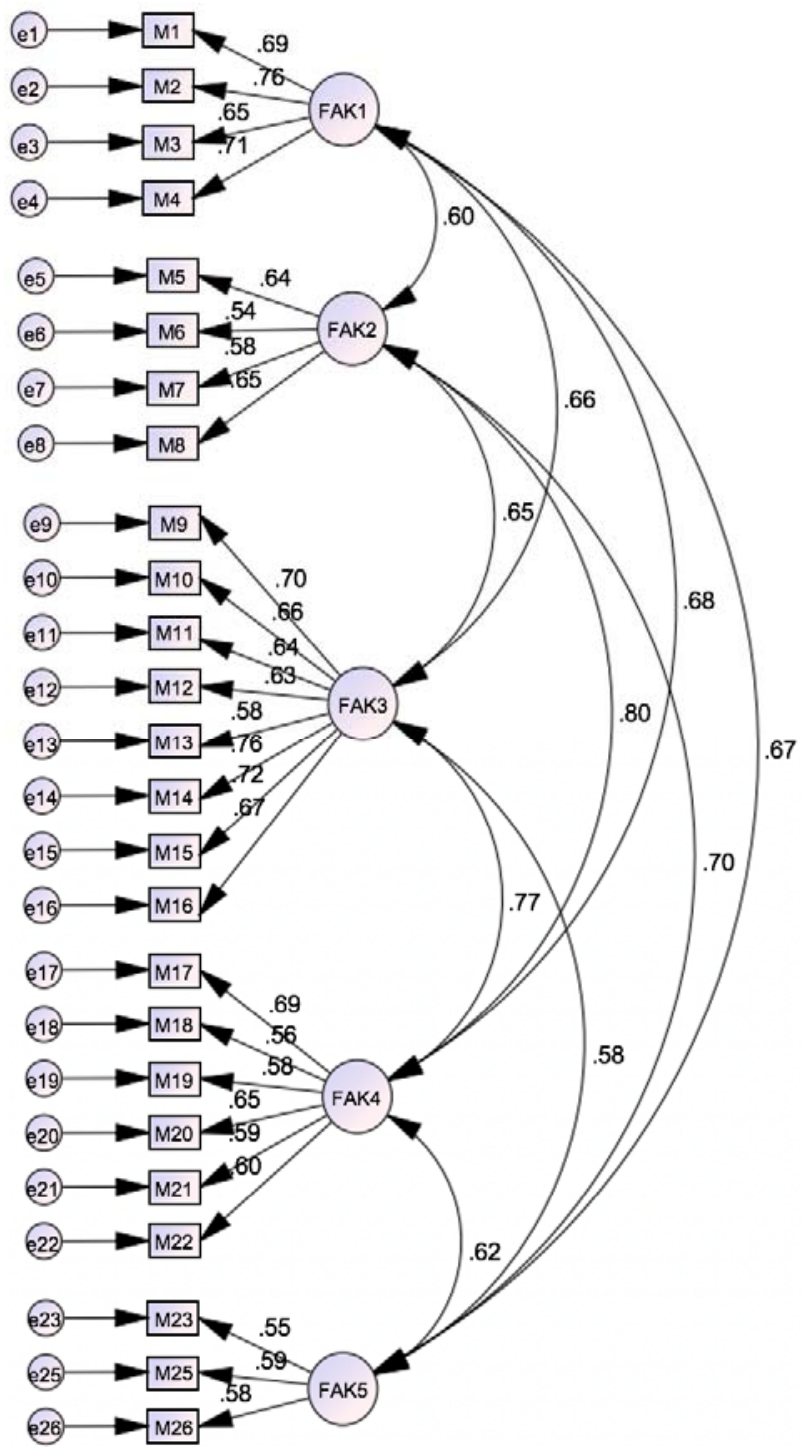

Şekil 1. İyi Öğretmen Ölçeği’nin Birinci Düzey DFA Sonuçları (Fak1[Faktör 1]: Öğretme ve öğrenme tutkusu, Fak2: Sosyal ve ahlaki boyut, Fak3: Yansitıc1 uygulayıc1, Fak4: Öğrenmeyi etkili planlanma ve yönetme, Fak5: Çocuklara/gençlere sevgi) 
Modifikasyonlar yapıllırken kuramsal gerekçeye ve hata terimleri ilişkilendirilen maddelerin aynı faktör altında yer almasına dikkat edilmiştir (Çokluk ve diğ., 2016; Karagöz, 2016). İnceleme sonucunda ölçeğin yansıtıcı uygulayıcı alt boyutunda aralarında gizil bir ilişkinin kabul edilebileceği ve model uyumuna anlamlı katkı sağlayacağı düşünülen iki madde (M18 ve M22) arasında modifikasyon yapılmasına karar vermiştir. Modele katkı sağlayacağı önerilen modifikasyon önerileri işleme alındıktan sonra yenilenen DFA sonucunda İÖÖ'nün Türkçe formunun beş faktörlü 25 maddeli yapısına yönelik oluşturulan modelin gerekli olan tüm uyum indekslerinde önemli iyileşmeler olduğu ve doğrulandığı bulunmuştur.

DFA sonucunda elde edilen beş boyutlu modelin uyum indekslerinin yeterli olduğu bulunmuştur. Doğrulanan modele ilişkin uyum indeksleri değerleri şöyledir: $(\chi 2 / \mathrm{sd}=$ $2.34, \mathrm{CFI}=.95$, TLI $=.94, \mathrm{GFI}=.93, \mathrm{RMSEA}=.058)$. Bu değerler, ÏÖÖ'nün orijinal formundaki beş faktörlü yapının Türk kültürü için de geçerli olduğu sonucunu vermektedir. Ölçeğin beş faktörlü yapısında yer alan gizil değiş̧enlerin ölçülmek istenen esas değişkeni bir diğer ifade ile bir üst boyutu ne kadar temsil ettiğini belirlemek için (Çelik ve Yılmaz, 2013) ikinci düzey model oluşturulmuş ve bu beş faktörün birlikte iyi öğretmen farkındalı̆̆ını ölçümleyip ölçümlemediği yapısal olarak DFA ile belirlenmiş̧ir. Çünkü İyi Öğretmen Ölçeği'nin alt boyutları ile tek bir genel yapıyı oluşturması ve toplam puanı vermesi de beklenmektedir. İkinci düzey DFA sonucunda elde edilen model Şekil 2'de sunulmuştur. 


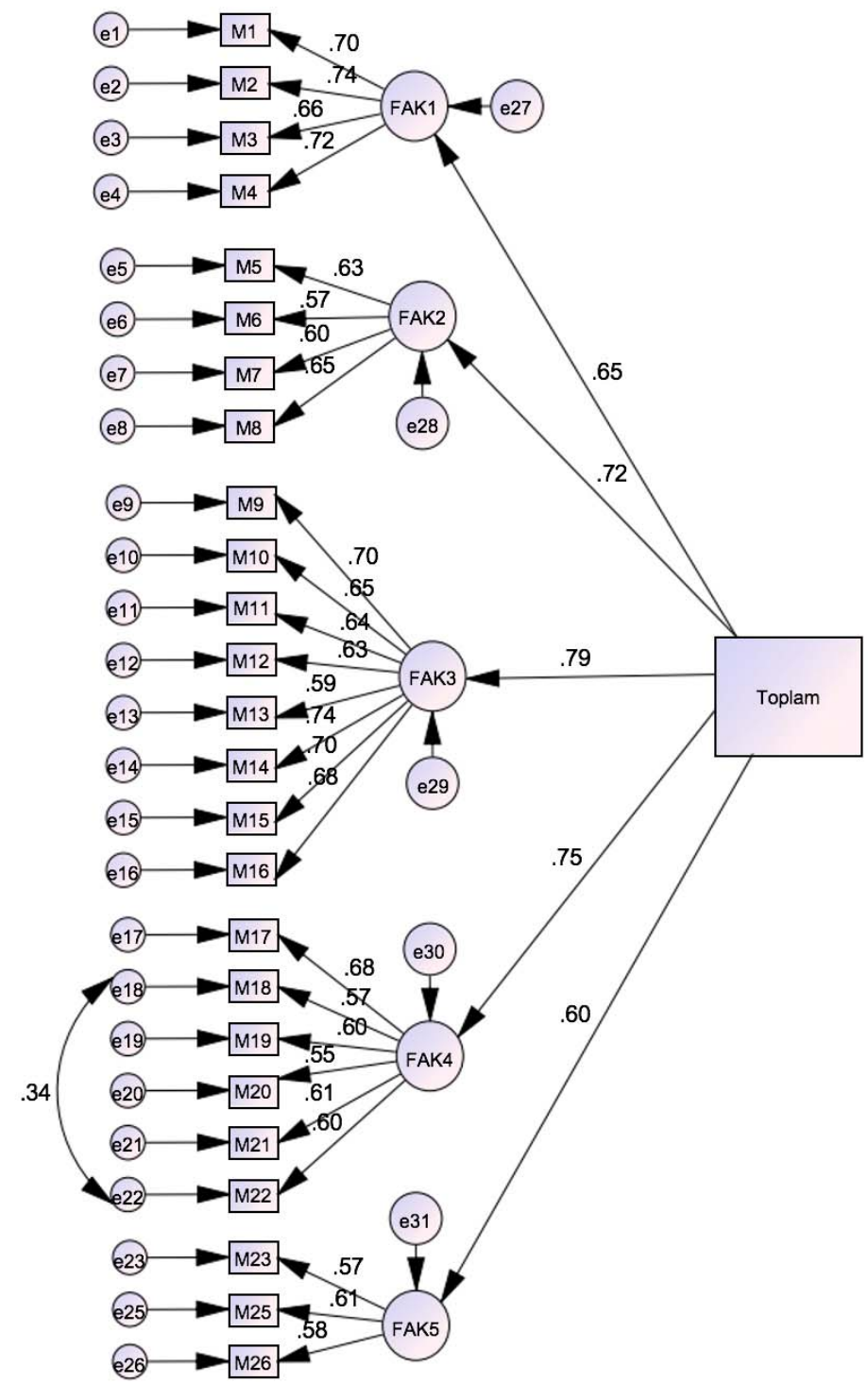

Şekil 2. İyi Öğretmen Ölçeği İkinci Düzey DFA ile Elde Edilen Model

İyi Öğretmen Ölçeği için yapılan ikinci düzey DFA sonuçlarına göre, ölçeği oluşturan tüm faktörlerin iyi öğretmen farkındalığı üzerinde anlamlı bir etkisinin olduğu bulunmuştur. Ölçek için test edilen modelin iyi uyum değerlerine sahip olduğu 
görülmüştür. İkinci düzey $\mathrm{DFA}^{\prime} \mathrm{da}$ uyum indeksleri; $\chi^{2} / \mathrm{sd}=2.54$, RMSEA=.054, $\mathrm{TLI}=.94, \mathrm{CFI}=.96$ ve $\mathrm{GFI}=.95$ olarak elde edilmiştir. Bu değerler öğretmen adaylarının iyi öğretmen olgusuna dair bakış açılarının öğretme ve öğrenme tutkusu, sosyal ve ahlaki boyut, yansıtıcı uygulayıcı, öğrenmeyi etkili planlanma ve yönetme ve çocuklara/gençlere sevgi şeklinde tanımlanan beş faktörlü bir yapı ile ölçülebileceğini göstermektedir. Bu bulgu, ölçekten toplam puan almanın da uygun olduğu sonucunu vermektedir.

\section{İyi Öğretmen Ölçeğinin Güvenirliğine İlişkin Bulgular}

İyi Öğretmen Ölçeği'nin güvenirliği ile ilgili kanıt sağlamak için Cronbach Alfa iç tutarlık katsayısı hesaplanmıştır. Ayrıca ölçekte yer alan maddelerin ölçtükleri özellik açısından kişileri ayırt etmede ne kadar yeterli olduklarının incelenmesi için düzeltilmiş madde-toplam korelasyon katsayıları incelenmiştir. Ölçekteki 25 maddenin ayırt edicilik gücünü hesaplamak için yapılan analizler sonucunda, ölçek maddelerinin düzeltilmiş madde-toplam korelasyon katsayılarının .487 ile .765 arasında değiştiği görülmüştür. Ölçeğin düzeltilmiş madde-toplam korelasyon katsayıları ölçme aracındaki maddelerin ölçülmek istenen özelliği ölçtüğünü göstermektedir (Büyüköztürk, 2017). Güvenirlik analizleri sonucunda ise ölçeğin tümüne ilişkin Cronbach Alfa iç tutarlık katsayısının .86 olarak bulunmuştur. Ölçeğin faktörlerinin iç tutarlık katsayıları "öğretme ve öğrenme tutkusu” faktörü için .81; "sosyal ve ahlaki boyut" faktörü için .80, "yansıtıcı uygulayıcı" faktörü için .78, "öğrenmeyi etkili planlanma ve yönetme" faktörü için .77 ve "çocuklara/gençlere sevgi" faktörü için .82 olarak hesaplanmıştır. Uzmanlar güvenirlik katsayısının .70 ve üzerinde olmasını test puanları için yeterli olduğunu belirtmiştir (Büyüköztürk, 2017). Bu değerler dikkate alındığında İyi Öğretmen Ölçeği'nin güvenirlik katsayılarının yeterli olduğu ifade edilebilir. 


\section{TARTIŞMA ve SONUÇ}

$\mathrm{Bu}$ araştırmada Devine ve diğerleri (2013) tarafından geliştirilen İyi Öğretmen Ölçeği’nin Türk kültürüne uyarlanması ve ölçeğin Türkçe formunun Türk örnekleminde geçerlik ve güvenirlik çalışmalarının yapılması amaçlanmıştır. Uyarlama çalışmaları doğrultusunda birinci aşamada orijinal ölçeğin dil eşdeğerliği çalışması yapılmıştır. Bu kapsamda 26 maddelik ölçeğin orijinal formu alanında uzman kişiler tarafından İngilizceden Türkçeye çevrilmiştir. Bu adımdan sonra geri çeviri yöntemine geçilmiş ve ölçek Türkçeden İngilizceye çevrilerek tekrar uzman görüşlerine başvurulmuştur. Ölçeğin uyarlama çalışmaları sonucunda ölçeğin Türkçe formunun orijinal ölçek ile eşdeğerliğinin kabul edilebileceği görülmüştür.

İyi Öğretmen Ölçeği’nin yapı geçerliği birinci ve ikinci düzey doğrulayıcı faktör analizleri yapılarak test edilmiştir. Yapılan birinci düzey DFA sonucunda ölçeğin uyum indekslerinin kritik değerlerin altında olduğu bulunmuştur. DFA sonucunda orijinal ölçekte "çocuklara/gençlere sevgi" alt boyutunda yer alan bir maddenin regresyon yük değerinin .30'un altında olduğu görülmüş ve alt boyuttaki toplam madde sayısı kontrol edilerek ilgili maddenin ölçekten çıkarılmasının alan yazında sınır kabul edilen faktör başına en az üç madde kriterini (Little, Lindenberger ve Nesselroade, 1999; Marsh, Hau, Balla ve Grayson, 1998) sağlaması nedeniyle sorun yaratmayacağı kararı verilmiştir. Ölçek maddelerinin incelenmesinin ardından kurulan modelde yeterli uyum indeksleri elde etmek ölçekte yer alan iki maddeye ait hatalar ilişkilendirilerek modifikasyon yapılmıştır. Modifikasyon önerileri sonucunda geriye kalan 25 madde ile yinelen DFA sonuçları ölçeğin uyum indeksleri değerlerinde önemli iyileşmeler olduğunu ve beş faktörlü yapının ise doğrulandığını göstermiştir. Araştırmada birinci düzey DFA sonucunda ölçeğin beş faktörlü yapısının iyi öğretmen farkındalığı olarak tanımlanan yapının bileşenleri olup olmadığını belirlemek için ikinci düzey DFA gerçekleştirilmiştir. İkinci düzey DFA sonucunda model uyumunun ve uyum indekslerinin iyi düzeyde olduğu bulunmuştur. Bu doğrultuda İÖÖ’de hem alt boyutlar temelinde puan alınması hem de bir üst kavram olan iyi öğretmen hakkındaki 
farkındalığa yönelik toplam puanın (tek bir genel yapıyı oluşturma) elde edilmesi mümkündür. Buna göre ölçeğin beş faktörlü orijinal yapısının Türkiye'de üniversite öğrencilerinden elde edilen verilerle doğrulandığı ifade edilebilir. İÖÖ’nün Türkçe formunun güvenirliğini belirlemek için ölçeğin ve alt boyutlarına ilişkin Cronbach Alpha iç tutarlık katsayıları hesaplanmıştır. Ölçeğin bütünü için hesaplanan iç tutarlık katsayısı .86 olarak bulunmuştur. İç tutarlık katsayıları "öğretme ve öğrenme tutkusu" faktörü için .81, "sosyal ve ahlaki boyut" faktörü için .80, "yansıtıcı uygulayıcı" faktörü için .78, "öğrenmeyi etkili planlanma ve yönetme" faktörü için .77 ve "çocuklara/gençlere sevgi” faktörü için .82 olarak bulunmuştur. Cronbach Alpha iç tutarlık katsayısının .70'in üzerinde olması ölçeğin güvenirliğine işaret etmektedir (Kline, 2005). Ayrıca ölçeğin maddelerine ait madde toplam puan korelasyonu incelendiğinde ulaşılan sonuçlar ölçek maddelerinin yüksek düzeyde ayırt ediciliğge sahip olduğunu göstermiştir. Sonuç olarak tüm bulgular İyi Öğretmen Ölçeği'nin Türkçe formunun öğretmen adaylarının iyi bir öğretmenin özellikleri hakkındaki farkındalıklarını ölçmek için yeterli psikometrik özellikler gösterdiğini ortaya koymuştur.

Araştırmada elde edilen bulgulara dayanılarak Türk kültürüne uyarlanan İÖÖ'nün beş faktörlü olmasından dolayı öğretmenlerin iyi öğretmen özellikleri hakkındaki farkındalık düzeylerini belirlemek isteyen araştırmacılar ve uygulayıcılar için ek bir fayda sağlayabilir. Ölçek öğretmenlerin iyi bir öğretmen hakkındaki önem verdikleri unsurların ne olduğunu belirlemeye ayrıca yardımcı olacaktır. Çünkü İÖÖ öğretmenlik mesleğinde kişisel, ahlaki, sosyal, mesleki gelişim, ayrıca öğrenme ve öğretimin bütünselliğini, öğretme işinin netliğini ve yansıtıcıllı̆ını temele alan pedagoji ve etkili öğretmen üzerine temellendirilmiştir. Bu bakımından gelecekte İyi Öğretmen Ölçeği ile yapılacak çalışmaların hem öğretmen adaylarının hem de öğretmenlerin iyi bir öğretmen hakkındaki önem verdikleri unsurların ne olduğunu anlamaya yardımcı olacağı öngörülmektedir. 
Ölçek yoluyla iyi öğretmen imajının incelenmesi hem mesleki hem de eğitimsel uygulamaların anlaşılmasını ve öğretmen eğitimi sürecinin bu algılara etkilerini saptamayı mümkün kılabilir. Ölçeğin kullanımı ile farklı kurumlarda, çeşitli branşlarda ve kıdemlerde olan öğretmenlerin iyi öğretmen olgusu hakkındaki algıları ölçülebilir. Ayrıca ölçek öğretmenlerin iyi öğretmen hakkında ne düşündüklerini ve iyi öğretmeni kendi koşullarına uygunluğu açısından nasıl değerlendirdiklerini görmeye yardımcı olabilir. Bu ölçeğin kullanımı ile öğretmen adaylarının iyi öğretmen hakkındaki düşünme şekillerinin inceleneceği çalışmalar yapılarak öğretmen yetiştirme alanına da katk1 sağlanacağı düşünülmektedir. İyi öğretmen algıları ile ilgili çalışmalar iyi öğretmeni neyin oluşturduğuna dair fikir ve düşüncelerin daha iyi anlaşılmasını, iyi bir öğretmen olmak için gereken kişisel niteliklerin ve pedagojik yeterliklerin tartışılmasını sağlayabilir. Bu anlamda İÖÖ yoluyla iyi öğretmen hakkındaki algıları araştırmak iyi bir öğretmeni neyin geliştirdiğine dair araştırmacılara, eğitimcilere daha fazla fikir verecektir. 


\section{KAYNAKLAR}

Ægisdóttir, S., Gerstein, L. H., \& Çinarbaş, D. C. (2008). Methodological issues in cross-cultural counseling research: Equivalence, bias, and translations. The counseling psychologist, 36(2), 188-219.

Alpar, R. (2013). Uygulamalı çok değişkenli istatistiksel yöntemler. Ankara: Detay Yayin.

Arnon, S., \& Reichel, N. (2007). Who is the ideal teacher? Am I? Similarity and difference in perception of students of education regarding the qualities of a good teacher and of their own qualities as teachers. Teachers and Teaching, 13(5), 441-464.

Arthur, J., Kristjánsson, K., Cooke, S., Brown, E., \& Carr, D. (2015). The good teacher: Understanding virtues in practice: Research Report. Birmingham: University of Birmingham, Jubilee Centre for Character and Virtues. Erişim http://epapers.bham.ac.uk/1970/1/The_Good_Teacher_Understanding_Virtues_i n_Practice.pdf adresinden 12.06.2020 tarihinde yapılmıştır.

Aypay, A. (2011). Behavioral habits of primary and secondary teachers and their perceptions on the characteristics of a "Good teacher". Elementary Education Online, 10(2), 620-645.

Azer, S. A. (2005). The qualities of a good teacher: how can they be acquired and sustained?. Journal of the Royal Society of Medicine, 98(2), 67-69.

Barnett, R. (1994). The limits of competence: Knowledge, higher education and society. Buckingham: Open University Press.Brown, T. A. (2006). Confirmatory factor analysis for applied research. New York: Guilford Press.

Becker, B. J., Kennedy, M., \& M., Hundersmarck, S. (2003). Hypothesis about 'quality': A decade of debates. Paper presented at the annual meeting of the American Educational Research Association.

Beishuizen, J. J., Hof, E., Van Putten, C. M., Bouwmeester, S., \& Asscher, J. J. (2001). Students' and teachers' cognitions about good teachers. British Journal of Educational Psychology, 71(2), 185-201.

Benekos, P. J. (2016). How to be a good teacher: Passion, person, and pedagogy. Journal of Criminal Justice Education, 27(2), 225-237.

Biesta, G. (2015). How does a competent teacher become a good teacher? On judgement, wisdom and virtuosity in teaching and teacher education. In R. Heilbronn \& L. Foreman Peck (Eds), Philosophical perspectives on the future of teacher education (pp.3-22). Oxford: Wiley Blackwell. 
Black, R. S., \& Howard-Jones, A. (2000). Reflections on best and worst teachers: An experiential perspective of teaching. Journal of Research and Development in Education, 34, 1-13.

Borich, G. (2014). Effective teaching methods (7th ed.). New York, NY: Macmillan.

Büyüköztürk, Ş. (2017). Sosyal bilimler için veri analizi el kitabı (23. Baskı). Ankara: Pegem A Yayın.

Byrne, B. M. (1998). Structural equation modeling with LISREL, PRELIS, and SIMPLIS: Basic concepts, applications, and programming. Mahwah: Lawrence Erlbaum Associates, Inc.

Çelik, H. E. ve Yılmaz, V. (2013). Lisrel 9.1 ile yapısal eşitlik modellemesi: Temel kavramlar uygulamalar programlama (2.bask1). Ankara: Anı Yayıncılık

Çokluk, Ö., Şekercioğlu, G., ve Büyüköztürk, Ş. (2016). Sosyal bilimler için çok değişkenli istatistik SPSS ve LISREL uygulamaları (4. Baskı.). Ankara: Anı Yayın.

Connell, R. (2009). Good teachers on dangerous ground: Towards a new view of teacher quality and professionalism. Critical Studies in Education, 50(3), 213229.

Cruickshank, D. R., \& Haefele, D. (2001). Good teachers, plural. Educational Leadership, 58(5), 26-30.

Deniz, L. (1998). Çağdaş öğretmen, başarılı öğretmen, iyi öğretmen-öğretmen adaylarının görüşlerine dayanılarak yapılan bir ön değerlendirme. $M$. Ü. Atatürk Eğitim Fakültesi Eğitim Bilim. Dergisi, 10(10), 83-95.

Devar, K. (2002). On being a good teacher. Journal of Hospitality, Leisure, Sport and Tourism Education. 1(1), 61- 67.

Devine, D., Fahie, D., \& McGillicuddy, D. (2013). What is 'good 'teaching? Teacher beliefs and practices about their teaching. Irish Educational Studies, 32(1), 83108.

Dewar, K. (2002). On being a good teacher. Journal of Hospitality, Leisure, Sport and Tourism Education, 1(1), 61-67.

Finney, S. J., \& DiStefano, C. (2006). Non-normal and categorical data in structural equation modeling. In G. R. Hancock and R. O. Mueller (Eds.), Structural equation modeling: A second course (pp. 269-314). Greenwich: Information Age.

Grant, K. A. (2015). From lists to images: Exploring the concept of the good teacher in teacher education. Journal of the Canadian Association for Curriculum Studies, 13(1), 36-59.

Hammer, D., Piascik, P., Medina, M., Pittenger, A., Rose, R., Creekmore, F., Scott, S. (2010). Recognition of teaching excellence. American Journal of Pharmaceutical Education, 74(9), 1-11. 
Harden, R.M., \& Crosby, J.R. (2000). The good teacher is more than a lecturer the twelve roles of the teacher. Medical Teacher, 22(4), 334-347.

Harrington D. (2009). Confirmatory factor analysis. Oxford University Press; New York.

Hoşgörür, T. (2012). A discussion of what makes a good teacher: Opinions of preservice primary school teachers. International Conference on New Horizons in Education (INTE2012). Procedia, Social and Behavioral Sciences, 55, 451- 460.

Howes, C., Whitebook, M., \& Phillips, D. (1992). Teacher characteristics and effective teaching in child care: Findings from the National Child Care Staffing Study. Child and Youth Care Forum, 21, 399-414.

Hu, L., \& Bentler, P. M. (1999). Cutoff criteria for fit indexes in covariance Structure analysis: Conventional criteria versus new alternatives. Structural Equation Modeling, 6, 1-55.

Hummerstone, H. K. M., \& Parsons, S. (2020). What makes a good teacher? Comparing the perspectives of students on the autism spectrum and staff. European Journal of Special Needs Education. doi: 10.1080/08856257.2020.1783800

Hyland, T. (1994). Competence, education and NVQs: Dissenting perspectives. London: Cassell.

Inan, B. (2014). A cross-cultural understanding of the characteristics of a good teacher. The Anthropologist, 18(2), 427-432.

Işıktaş, S. (2015). Öğretmen adaylarının iyi öğretmen olma ile ilgili görüşleri. Hacettepe Üniversitesi Eğitim Fakültesi Dergisi. 30(4), 119-131.

Jo-Anne, R. (2011). What does good teacher education research look like? Asia-Pacific Journal of Teacher Education, 39(3), 177-182.

Jöreskog, K. G. \& Sorbom, D. (1996). LISREL 8 reference guide. Scientific software international. IL: Lincolnwood.

Karagöz, Y. (2016). SPSS ve AMOS 23 uygulamalt istatistiksel analizler. İstanbul: Nobel Yayınevi.

Kember, D., Jenkins, W., \& Chi Ng, K. (2004). Adult students' perceptions of good teaching as a function of their conceptions of learning-Part 2. Implications for the evaluation of teaching. Studies in Continuing Education, 26(1), 81-97.

K1zıltepe, Z. (2002). İyi ve etkili öğretmen. Eğitim ve Bilim, 27, 10-14.

Kline, R. B. (2005). Principles and practice of structural equation modeling (Second. Bask1.). New York, NY: Guilford Publications, Inc.

Korthagen, F., A., J. (2004). In search of good teachers: towards a more holistic approach in teacher education. Teaching and Teacher Education, 20, 77-97.

Kutnick, P., \& Jules, V. (1993). Pupils' perceptions of a good teacher: a developmental perspective from Trinidad and Tobago. British Journal of Educational Psychology. 63, 400-413. 
Lavy, I., \& Shriki, A. (2008). Investigating changes in prospective teachers' views of a 'good teacher'while engaging in computerized project-based learning. Journal of Mathematics Teacher Education, 11(4), 259-284.

Little, T. D., Lindenberger, U., \& Nesselroade, J. R. (1999). On selecting indicators for multivariate measurement and modeling with latent variables: When" good" indicators are bad and" bad" indicators are good. Psychological methods, 4(2), 192-211.

Malik, A. N., \& Bashir, S. (2015). Good teacher. The Professional Medical Journal, 22(05), 670-673.

Markert, R. J. (2001). What makes a good teacher? Lessons from teaching medical students. Academic Medicine, 76(8), 809-810.

Marsh, H. W., Hau, K. T., Balla, J. R., \& Grayson, D. (1998). Is more ever too much? The number of indicators per factor in confirmatory factor analysis. Multivariate Behavioral Research, 33(2), 181-220.

McIntyre, T., \& Battle, J. (1998). The traits of "good teachers" as identified by AfricanAmerican and white students with emotional and/or behavioral disorders. Behavioral Disorders, 23, 134-142.

MEB. (2006). Öğretmenlik mesleği genel yeterlilikleri. Öğretmen Yetiştirme ve Eğitimi Genel Müdürlüğü. http://otmg.meb.gov.tr/YetGenel.html adresinden 26.06.2020 tarihinde edinilmiştir.

MEB. (2006). Öğretmenlik mesleği genel yeterlilikleri. Öğretmen Yetiştirme ve Eğitimi Genel Müdürlüğü. http://otmg.meb.gov.tr/YetGenel.html adresinden 26.06.2020 tarihinde edinilmiştir.

Moore, A. (2004). The good teacher: Dominant discourses in teaching and teacher education. Abingdon: Routledge.

Morrison, B. \& Evans, S. (2018). University students' conceptions of the good teacher: A Hong Kong perspective. Journal of Further and Higher Education, 42(3), 352-365.

Mullock, B. (2003). What makes a good teacher? The perceptions of postgraduate TESOL Students. Prospect 18 (3), 3-23.

Murphy, P. K., Delli, L. A. M., \& Edwards, M. N. (2004). The good teacher and good teaching: Comparing beliefs of second-grade students, preservice teachers, and inservice teachers. The Journal of Experimental Education, 72(2), 69-92.

Noddings, N. (1992). Professionalization and mathematics teaching. In D. A. Grouws (Ed.), Handbook of research on mathematics teaching and learning (pp. 197208). New York: Macmillan Pub.

Oruç, N. (2008). A Comparison of the Turkish and European student-teachers' definition of a good teacher. Gazi University Journal of Gazi Educational Faculty (GUJGEF), 28(2), 149-168. 
Patton, M. Q. (2014). Nitel araştırma yöntemleri, beş yaklaşıma göre nitel araştırma ve araştırma deseni. M. Bütün ve S. B. Demir (Çev. Ed.). Ankara: Siyasal Kitabevi.

Peterson, A., \& Arthur, J. (2020). Ethics and the Good Teacher: Character in the Professional Domain. Routledge.

Porter, A.C., \& Brophy, J.E. (1987). Good teaching: Insights from work of the Institute for Research on Teaching. Occasional PAPER No.114, East Lansing: The Institute for Research on Teaching. Michigan State University.

Reid, J. A., Singh, M., Santoro, N., \& Mayer, D. (2011). What does good teacher education research look like? Asia-Pacific Journal of Teacher Education, 39(3), 177-182.

Sanders, S. E. (2002). What do schools think makes a good mathematics teacher? Educational Studies, 28(2), 181-191.

Schermelleh-Engel, K., Moosbrugger, H., \& Müler, H. (2003). Evaluating the fit of structural equation models: Tests of significance and descriptive goodness-of-fit measures. Methods of Psychological Research Online, 8(2), 23-74.

Sireci, S.G., Patsula, L., \& Hambleton, R.K. (2005). Statistical methods for identifying flaws in the test adaptation process. R.K. Hambleton, P.F.Merenda \& C.D. Spielberger (Ed.) Adapting educational and psychological tests for crosscultural assessment (pp. 93-135). Lowrence Erlbaum Associates, Publishers Mahwah:Mahwah.

Stobaugh, R., Mittelberg, J., \& Huang, X. (2020). Examining K-12 students' perceptions of student teacher effectiveness. Teacher Development, 24(2), 274292.

Stronge, J. H., Ward, T. J., \& Grant, L. W. (2011). What makes good teachers good? A cross case analysis of the connection between teacher effectiveness and student achievement. Journal of Teacher Education, 62(4), 339-355.

Tabachnick, B. G., \& Fidell, L. S. (2013). Using multivariate statistics. Pearson \& Allyn and Bacon.

Thomas, J. A. (1998). On becoming a good teacher: Reflective practice with regard to children's voices. Journal of Teacher Education, 49, 372-380.

Ubuz, B. ve Sarı, S. (2009). Sınıf öğretmeni adaylarının iyi öğretmen olma ile ilgili görüşleri. Ondokuz Mayıs Üniversitesi. Eğitim Fakültesi Dergisi. 28, 53-61.

Walker, R. J. (2008). Twelve characteristics of an effective teacher: A longitudinal, qualitative, quasi-research study of in-service and pre-service teachers' opinions. Educational Horizons, 87(1), 61-68.

Wilson, M., Cooney, T. J., \& Stinson, D. W. (2005). What constitutes good mathematics teaching and how it develops: Nine high school teachers' perspectives. Journal of Mathematics Teacher Education, 8, 83-111. 
Winch, C. (2017). The good teacher. Teachers' know-how: A philosophical investigation (pp. 187-201). John Wiley

\section{ORCID}

İlhan ILTER (D) https://orcid.org/0000-0002-1473-7172 


\section{SUMMARY}

\section{Introduction}

The issue of training qualified teachers in education and increasing teacher professionalism is one of the most emphasized and discussed issues. It is widely accepted that teachers are the single most important determinant of the quality of education. Teachers, who have an important place in the education system, are seen as potential saviors of the education system. Teachers are one of the most influential and powerful forces for equity, access and quality in education and are the key to sustainable global development. As a matter of fact, the main way to create a professional learning community and improve educational outcomes in a country is to increase teacher professionalism. Although there is a long tradition of research on the phenomenon of good teachers in international literature (eBenekos, 2016; Connell, 2009; Devar, 2002; Grant, 2015; Hummerstone \& Parsons, 2020; McIntyre \& Battle, 1998; Kember, Jenkins \& Chi-Ng, 2004; Miller, 2012; Morrison \& Evans, 2018; Mullock, 2003; Kutnick \& Jules, 1993; Peterson \& Arthur, 2020; Reid, Singh, Santoro, and Mayer, 2011; Thomas, 1998), studies focused on the best teacher profile in Turkey is not yet at a sufficient level. In addition, there is no evidence of an assessment tool to evaluate the level of awareness about the characteristics of good teachers in Turkey. It has been concluded that studies on good teachers are mostly qualitative. For these reasons, in this study, the adaptation study of the Good Teacher Scale (Good Teacher Questionnaire) developed by Devine, Fahie, and McGillicuddy (2013) into Turkish culture was conducted.

The reason why the Good Teacher Scale has been adapted to Turkish culture is that the scale represents various aspects of being a qualified teacher in the teaching profession, providing a useful framework for determining the level of awareness of prospective teachers or teachers who are currently teaching. The scale provides a perspective that will provide a framework for what constitutes the essence of a good teacher or basic indicators of what a good teacher is. These indicators include a number of different classifications, such as planning and managing learning effectively, love of children, social and moral awareness, reflective practice behaviors, professional growth, self-critical practices, and student relations (Devine et al., 2013). In order to achieve the desired quality and success in the education system, there is a need for research based on determining the basic criteria of what constitutes the essence of a good teacher. It is important to determine the awareness of the teachers of the teaching profession or tomorrow's teachers of the phenomenon of good teachers and to examine whether they have good teacher indicators. Because good teacher research contributes to the basic knowledge that determines the design of teacher education programs and the work of teacher educators. In addition, a better understanding of the ideas and thoughts about what constitutes a good teacher can help to create mechanisms to discuss and measure the qualifications required by the teaching profession in order to be a good teacher. On the other hand, up-to-date ideas about what constitutes a good teacher are embedded in the design of educational institutions, and good teachers gain an important place in new understandings and practices about effective teacher education mechanisms (Connell, 2009). In this context, the study of adapting the Good Teacher Scale developed by Devine et al. (2013) to Turkish culture is considered useful both as a resource for 
measuring the notion of good teachers in the Turkish Education System and for discussing new ideas, approaches, and knowledge on improving teacher professionalism, which constitutes the main purpose of this study.

\section{Method}

This study is a scale adaptation study in which the Good Teacher Scale is adapted to Turkish culture. In the study, a survey model, one of the descriptive research designs, was used. Within the scope of the study, it aimed to ensure the language equivalence of the scale, to examine the construct validity and to carry out reliability studies.

\section{Results}

The CFA results indicated that, the 5-factor structure in the original form of the scale ("Passion for teaching and learning", "Social and moral dimension", "Reflective practitioner", "Effective planning and management of learning" and "Love for children / young people") was confirmed in the Turkish sample. The Cronbach Alpha coefficient calculated for the whole scale is .86; The internal consistency coefficients calculated for the factors in the scale ranged from .77 to .82 . The findings of the study show that the Good Teacher Scale, which was adapted to Turkish culture, is a valid and reliable measurement instrument for exploring teacher candidates' awareness of the characteristics of good teachers.

\section{Discussion}

Adapted to Turkish culture based on the validity and reliability findings of this study, it provides an additional benefit for researchers and practitioners who want to measure the awareness level of teachers about good teacher traits, since it has five factors. The scale is based on personal, moral, social, and professional development in the teaching profession, as well as on the integrity of learning and teaching, and on pedagogy and effective teaching, which are based on the clarity and reflectivity of teaching work. It is anticipated that future research to be conducted with the Good Teacher Scale will help both prospective teachers and teachers understand what the factors that they attach importance to a good teacher. Examining the image of good teachers through the scale may make it possible to understand both professional and educational practices and to determine the effects of the teacher education process on these perceptions. By using this scale, the perceptions of teachers in different institutions, in various branches, and seniority, about the concept of good teachers can be measured. 
Ek 1. Etik Kurul İzin Belgesi

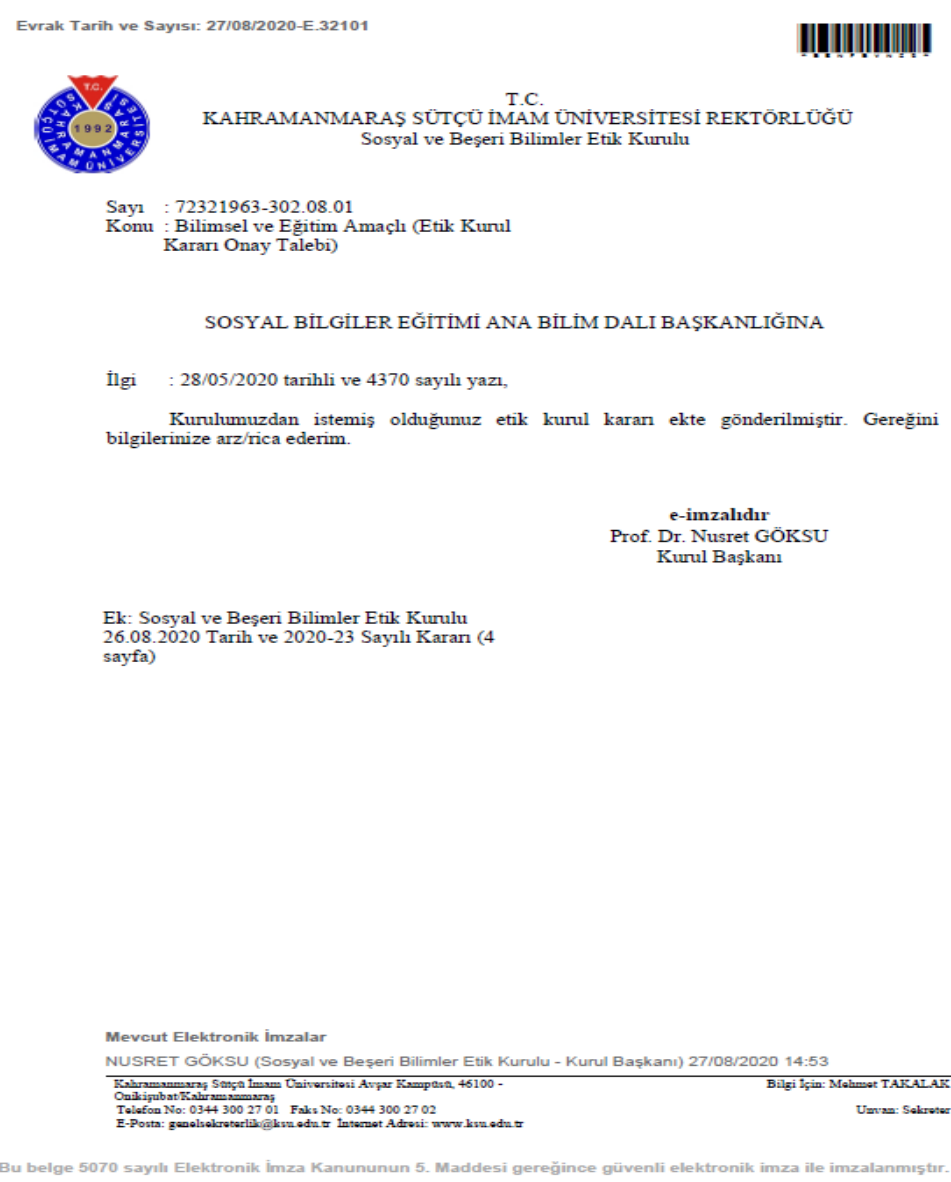


KARAR 5 :

Doç. Dr. İlhan İLTER'in 28.05.2020 Tarihli dilekçesi ve ekleri Prof. Dr. Nail YILDIRIM (raportör) 24.08.2020 tarih ve E. 31621 sayllı raporu görüșüldü.

Üniversitemiz Öğretim Üyelerinden Doç. Dr. İlhan İLTER'in "İyi Öğretmen Ölçeği: Türkçe'ye Uyarlama, Geçerlik ve Güvenirlik Çalışması " araștırma makalesi için çalışmasında kullanmak için uygulanacak açık uçlu görüşme formu (ankette yer alan soru, önerme ve/veya ölçeklerin alıntılanmasına yönelik akademik alıntılanma kurallarına uyma zorunluluğu araștırmayı yapan akademisyen ve varsa danıșmanlığını yaptığı öğrenciye ait olmak koşuluyla) Kahramanmaraş Sütçü İmam Üniversitesi Eğitim Fakültesi Farklı Programlarda öğrenim gören 3. ve 4. sınıf öğrencilerine uygulama talebinin uygun olduğuna oylama sonucunda oy birliği ile;

Karar verildi. 
